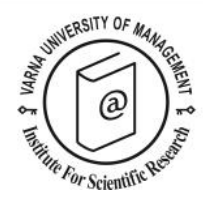

\title{
Introduction to the Special Issue on Digital Transformation in the Tourism Industry
}

\author{
GUEST EDITORS:
}

Maro Vlachopoulou ${ }^{1}$ and Konstantinos Fouskas ${ }^{2 *}$

${ }^{1}$ Department of Applied Informatics, University of Macedonia, Greece

2 Department of Applied Informatics, University of Macedonia, Greece. 156 Egnatia Street, Thessaloniki, 54636 Greece, Tel. +30.2310.891845, e-mail: kfouskas@uom.edu.gr.

${ }^{*}$ Corresponding author

Citation: Vlachopoulou, M. and Fouskas, K. (2022). Introduction to the Special Issue on Digital Transformation in the Tourism Industry. Editorial. European Journal of Tourism Research 30, 3001. 
The scope of this special issue has been to collect the latest theoretical and empirical research on Digital Transformation in the Tourism Industry, expanding the work presented in International Conference on Strategic, Innovative Marketing and Tourism (ICSIMAT) conference (http://icsimat.com/) that took place in the Athenian Riviera from the 17th to the 2oth of October 2018. A series of papers have been submitted revealing the major impact of technology advancements in the Tourism Industry and the role of digital transformation in the disruption of the tourism industry. A total of five papers were selected for publication in the special issue that were of high quality and in line with the scope of the Special issue and the European Journal of Tourism Research.

Issues like Smart tourism development have raised and pose a significant impact in tourism destinations and the tourism industry. The first paper deals with smart tourism development which has been adopted by destinations around the world to strengthen their long-term competitiveness in light of rapid technological, societal and environmental change. Destination management organizations (DMOs) are generally endowed with smart tourism governance at the destination-level and typically see it as a great opportunity to prove their relevance. However, these organizations also face enormous challenges and often lack the capacities and competencies needed to successfully govern smart destinations. While recent literature highlights the importance of smart destination governance, it does not provide much guidance in terms of the functions and roles of smart DMOs. This paper presents a preliminary conceptualization of six smart DMO functions that support smart governance roles, namely mobilizing, match-making, managing, sensing, shapeshifting and stewardship.

The second paper examines the impact of digital transformation in the demand side of the tourism industry and deals with the effects of digital transformation on a digitally educated generation, Generation Z. It presents the experiential values and online hotel booking in the digital transformation era of the tourism sector in relation to the Greek Generation Z cohort. More specifically, quantitative research conducted with an online questionnaire yielded a sample of 970 Generation Zers' responses. Using the Structural Equation Model via the AMOS statistical package, six hypotheses were tested. Results have revealed that the construct of experiential values positively impacts directly on patronage intentions, attitudes towards the e-booking platform, and customer involvement. Additionally, Generation Z members' attitudes towards the e-booking platform and involvement with the platform impacts patronage intentions. Furthermore, involvement with the e-booking platform has a negative effect on consumers' attitudes towards the platform. Detailed discussion of results and further implications is also provided.

The next paper examines the impact of digital transformation in the supply side of the tourism industry, and more specifically the roles of e-intermediaries. Many unexpected challenges for not only tourism businesses but also for travelers emerged when present-day shifts in economic, technological, social, and political factors and led to their quick and sudden growth. Although it was anticipated that the Internet would open up new opportunities in the tourism industry, especially in more choice and closer cooperation between consumers and suppliers, this has not been the case. When Cooper and Lewis said, "once the Cinderella of the marketing mix - unglamorous but essential - distribution is now seen as central to many economic sectors", it was impossible for them to predict what would follow in the tourism sector, particularly in the digital era. Online distribution channels changed the existing status of the tourism sector into highly efficient integrated channels from disorganized, loosely knit collections of organizations. Based on the hoteliers' opinions, it becomes clear that tourism professionals, taking into consideration of the recent changes in tourism distribution in the digital era, have to look out for new opportunities and threats within tourism distribution channels so that they will be able to remain competitive and successful. 
The succeeding paper expands the research on the impact of digital transformation in the supply side of the tourism industry by proposing and empirically validating a measure of brand evidence of Online Travel Agencies (OTA). This measure is representing all meaningful brand associations made by customers when evaluating the brand, and then investigates its effect in building strong consumerbrand relationships and creating favorable consumer behavioral intentions. To test the proposed model, a survey of 971 users of travel online booking platforms in Greece was conducted. Results fully support the validity of the proposed brand evidence index, as several OTA's brand related dimensions that a customer experiences during both the pre-purchase and usage stage shape the index expressing brand evidence. Furthermore, the findings confirmed the significant positive effects of brand evidence on both consumer-brand relationships and consumer behavioral intentions towards the brand.

The final paper is a systematic literature review focused on studies exploring smart tourism from a humanware approach, with specific theoretical and practical implications. An initial work, covering the papers published between 2008 and 2020, reveal five dimensions under a humaware approach: (i) smart technologies; (ii) smart ecosystems; (iii) value creation; (iv) tourism experience; and, (v) sharing economy. With this classification this paper aims to identify emerging trends and future research paths using a scientometric analysis of smart tourism research from 2008 to 2020 . The scientometric analysis was conducted over the 1321 papers referenced and retrieved from Web of Science and Google Scholar, narrowed to the 225 classified as tourism and hospitality. These articles were subject to content, citation and authorship analysis. The content analysis produced eight clusters that represent the main research streams. This result indicates the field's fast evolution path since two of these clusters emerged in the last three years. The twenty most cited articles were reviewed and classified under the humanware framework. The vast majority of the works are still related to smart ecosystems and technologies, unveiling the need to enrich knowledge related to the other streams and the tourism and hospitality response to Covid-19 supported by smart technologies.

The research in these papers provided a unique and holistic approach to the impact of digital transformation on the tourism industry, taking into consideration not only previous research on the subject but also the effects on the demand and supply side of the tourism industry, as well as the potential usage of emerging technologies and the emergence of unique aspects of smart tourism.

Received: 05/11/2020

Accepted: 28/04/2021 